3. Punjabi Food.-(a) Thick wheat chapatti with a lot of ghee (butter fat). (b) Dal urd (Phaseolus mungo) is made as a thick viscous curry with spices and chillies and a lot of ghee. (c) Rawan (Vigna sinensis) is made as thick curry after frying the beans; all the ingredients have a neutral reaction in vitro and no groupspecific substances. Punjabi food is taken simmering hot and requires a good deal of mastication.

\section{REFERENCES}

Boorman, Kathleen D., and Dodd, B. E. (1961). An Introduction to Blood Serology, 2nd ed., p. 63. Churchill, London.

Burnet, F. M. (1948). Aust. F. exp. Biol. med. Sci., 26, 71.

Dewar, Margaret R., and Parfitt, G. J. (1954). 7. dent. Res., 33, 596

Dogra, J. R. (1940). Indian f. med. Res., 28, 145.
Hadley, G. G. (1959). Indian Coun. med. Res. Rep., No. 31.

Hanke, M. T. (1937). Dent. Dig., 43, 235.

Malhotra, S. L. (1964). Gut, 5, 412.

- Majumdar, C. T., and Bardoloi, P. C. (1964). Ibid., 5, 355. Nour-Eldin, F., and Wilkinson, J. F. (1957). F. Physiol. (Lond.), 136, 324.

Raghvachari, C. (1959). Indian Coun. med. Res. Rep., No. 39, 48.

Sand, H. F. (1951). F. appl. Physiol., 4, 66

Somervell, T. H., and Orr, I. M. (1936). Brit. f. Surg., 24, 227.

Thaysen, J. H., Thorn, N. A., and Schwartz, I. L. (1954). Amer. F. Physiol., 178, 155.

Wechsler, A. (1959). The Secretion of Bicarbonate in Saliva, M.Sc. thesis, McGill University. Quoted from pp. 145-147 of Physiology of the Salivary Glands, by A. S. V. Burgen and N. G. Emmelin, 1961. Arnold, London.

Willsmore, N. M. (1937). Australian Dental Congress (9th) Transactions, p. 530 ; Aust. 7. Dent., 1937, 41, 161. Quoted from Dewar and Parfitt, 1954

Wig, K. L. (1959). Indian Coun. med. Res. Rep., No. 39, 70.

\title{
Results of Behaviour Therapy in 77 Psychiatric Patients
}

\author{
J. E. COOPER,* B.M., M.R.C.P., D.P.M. ; M. G. GELDER, † B.M., M.R.C.P., D.P.M., D.OBST. ; \\ I. M. MARKS, $\ddagger$ M.D., D.P.M.
}

Brit. med. F., 1965, 1, 1222--1225

Behaviour therapy has recently attracted interest and controversy, but results are still uncertain in view of conflicting reports. On the one hand, Wolpe (1958) has claimed that $90 \%$ of neurotic patients improved considerably with treatment, and similar enthusiastic reports have been made by Lazarus (1963). On the other hand, the only controlled follow-up study available (Cooper, 1963), although too small to allow definite conclusions to be reached, suggested that behaviour therapy had an advantage only in phobic patients. The frequent report of an improvement rate of about $70 \%$ in a mixed group of neurotic patients must be borne in mind when assessing these and other new therapeutic claims-for example, Giel et al. (1964).

The value of general statements about the effectiveness of therapy increases with the number of patients studied and with the degree of control available, and with this in mind the results of behaviour therapy in 77 psychiatric patients treated at the Bethlem Royal and Maudsley Hospitals and followed up for one year have been collected together in this paper. The patients suffered from a variety of neurotic disorders. Thirty of the 77 have already been reported by Cooper (1963), 31 who were treated for specific and generalized phobias are described in detail elsewhere (Marks and Gelder, 1965), and the remaining 16 (including 5 with obsessional neurosis and 8 with writers' cramp) are described here for the first time. The same method of retrospective comparison with control cases has been used for all the 77 patients, allowing them to be grouped together for the purpose of a general discussion of behaviour therapy (satisfactorily matched control cases were found for 55 out of the 77 patients).

\section{Assessment}

\section{Method}

This is described in detail elsewhere (Cooper, 1963 ; Marks and Gelder, 1965). Briefly, patients were included in the behaviour therapy groups only where they had five or more

\footnotetext{
* M.R.C. Unit for Study of Environmental Factors in Mental and Physical Illness, London School of Economics.

t Lecturer, Institute of Psychiatry, the Maudsley Hospital, London.

$¥$ Research Worker and Honorary Senior Registrar, Institute of Psychiatry and the Maudsley Hospital, London.
}

treatment sessions. A similar criterion was used for inclusion of controls, except for three with "other phobias" and two with writer's cramp, where owing to scarcity of cases fewer treatment sessions were accepted. (Any bias present from this would have favoured behaviour therapy.) Control cases with the same diagnoses, but who had had treatment other than behaviour therapy, were matched with the behaviour-therapy cases, first for sex and type of symptom, and then as closely as possible for age and for duration and severity of symptoms. All available information about patients' symptoms and activities before and after treatment was then extracted from the case-notes of both the behaviour-therapy and control cases, and put through a process of blind assessment by two independent judges. Assessments were made of the patients' state before treatment, at the end of treatment, and one month and one year after the end of treatment on a specific five-point symptom improvement scale and also on a general improvement scale. Results on the general improvement scale are not reported here as information on this aspect was too scanty.

Enuresis, encopresis, and school phobias were not included in this study.

\section{Clinical Features of the Various Groups}

Sixty-one of the patients have already been reported elsewhere, so their clinical features are only briefly noted.

Agoraphobias (29 cases-23 female).-These included fears of being alone, in the street or travelling. All were in-patients, and were severely handicapped by long-standing symptoms starting in early adult life-mean duration 10 years, mean age at treatment 34. Many had previous psychiatric admissions and other psychiatric symptoms. They were much more disabled than the patients of Wolpe (1958) and Lazarus (1963). Controls were well matched.

"Other Phobias" (12 cases-10 female).-These had mainly fears of specific objects-for example, animals, insects, thunder -and as so few were available they were harder to match with controls. Only two were in-patients, and all had phobias of very long standing, largely starting in early childhood-mean duration 19 years, mean age at treatment 28 . They were much 
less handicapped than the agoraphobics, with far fewer other psychiatric symptoms.

Obsessive Rituals (10 cases-9 female).-All were in-patients with well-matched controls-mean age at treatment 38 , mean symptom-duration 10 years. They were more severely ill than most of those designated obsessional by Wolpe (1958).

Writer's Cramp (13 cases-11 male).-These had moderately severe symptoms, and many had other minor psychiatric symptoms. Most were out-patients-mean age at treatment 40, mean symptom duration four years. Only six suitable controls could be found for them.

Miscellaneous (13 cases).- These were three cases of tic, three of stammer, and one each of fear of cancer, spasmodic torticollis, hyperventilation, fear of urinary incontinence, urinary frequency, aggressive outbursts, and hysterical ptosis.

\section{Treatment}

The treatment programmes for all except nine of the behaviour-therapy patients were devised and carried out by staff psychologists and postgraduate students under the general supervision of psychiatric consultants. The other nine were treated by psychiatric registrars. Treatment programmes were designed for each patient individually, based upon the usual principles of reciprocal inhibition, desensitization, relaxation, etc.-for details see Wolpe (1958), Eysenck (1960), and Meyer and Gelder (1963).

All phobic patients received graded practical retraining along the lines of Meyer and Gelder (1963). Eight agoraphobics and four "other phobics" also had desensitization in imagination along the lines of Wolpe (1958). In the obsessives a combination of both methods was used in most patients. Ten with writer's cramp had avoidance learning, and five had writing exercises. In addition, all patients were subject to the usual hospital influences and were given a variety of drugs, supportive interviews, and other treatments.

The controls received a wide variety of treatments; most received supportive interviews, sometimes alone and sometimes in combination with sedatives and tranquillizers. Only 10 received intensive psychotherapy.

\section{Results}

The Table shows that the overall improvement rate (all cases) at the end of treatment was $61 \%$ for patients receiving behaviour therapy and $44 \%$ for controls. A much smaller number-29\% and $22 \%$ respectively-were rated "much improved," and by the end of a year's follow-up both groups were equivalent.

\begin{tabular}{|c|c|c|c|c|c|c|}
\hline \multirow[b]{2}{*}{ Symptom Treated } & \multirow[b]{2}{*}{$\begin{array}{c}\text { No. } \\
\text { of } \\
\text { Cases }\end{array}$} & \multirow[b]{2}{*}{$\begin{array}{c}\text { Mean } \\
\text { No. } \\
\text { of } \\
\text { Sessions }\end{array}$} & \multirow{2}{*}{$\begin{array}{c}\text { Mean } \\
\text { Duration } \\
\text { of } \\
\text { Treat- } \\
\text { ment }\end{array}$} & \multicolumn{3}{|c|}{ Percentage Improved at } \\
\hline & & & & $\begin{array}{c}\text { End of } \\
\text { Treat- } \\
\text { ment } \\
(M I)\end{array}$ & \begin{tabular}{|} 
One \\
Month's \\
Follow- \\
up
\end{tabular} & $\begin{array}{c}\text { One } \\
\text { Year's } \\
\text { Follow- } \\
\text { up (MI) }\end{array}$ \\
\hline
\end{tabular}

\begin{tabular}{|c|c|c|c|c|c|c|c|}
\hline \multicolumn{8}{|c|}{ Results of Behaviour Therapy in 77 Cases } \\
\hline $\begin{array}{l}\text { Agoraphobia } \\
\text { Other phobias } \\
\text { Writer's cramp } \\
\text { Obsessive rituals } \\
\text { Miscellaneous . }\end{array}$ & $\begin{array}{l}\ldots \\
\cdots \\
\cdots \\
\ldots\end{array}$ & $\begin{array}{l}29 \\
12 \\
13 \\
10 \\
13\end{array}$ & $\begin{array}{l}56 \\
27 \\
44 \\
35 \\
\end{array}$ & $\begin{array}{l}6 \text { months } \\
4 \stackrel{\prime}{6}, " \\
4 \cong\end{array}$ & $\begin{array}{r}69(41) \\
100(58) \\
46(8) \\
30(10) \\
46(8)\end{array}$ & $\begin{array}{l}59 \\
\frac{91}{33+} \\
-\end{array}$ & $\begin{array}{l}72 *(52) \\
67(33) \\
42+(0) \\
33+(0) \\
38(15)\end{array}$ \\
\hline & & 77 & - & - & $61(29)$ & - & $55(27)$ \\
\hline
\end{tabular}

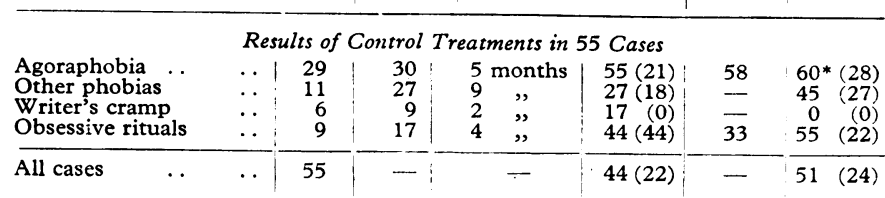

MI = Figures in parentheses indicating percentage "much improved." * Four cases lost.
t One case lost.
However, the mixed overall improvement rate masks an important differential response of patients according to differing neurotic syndromes. The worst results of behaviour therapy were in subjects with obsessive rituals and writer's cramp. Best results were in the phobics, especially the "other phobics," the latter showing an impressive $100 \%$ rate of improvement, though much of this was lost at follow-up. Results in the "other phobics" were greatly superior to those in their controls, but much less so in the agoraphobics. Marks and Gelder (1965) showed the greater improvement of those with agoraphobia during behaviour therapy (compared with control treatments) to be at least partly a function of increased frequency and duration of their treatment compared with that received by controls. The same study divided agoraphobia from "other phobias"for example, animals, insects, thunder-because detailed analysis showed them to differ according to clinical features: agoraphobia more often ran a fluctuating course associated with depression, generalized anxiety, and depersonalization, while the "other phobias" were more often a fairly circumscribed and continuous disturbance.

To enable distinctions to be made between slight and marked improvement, the Table shows the percentages "much improved " in parenthesis next to the crude improvement rates. These show a much smaller proportion of patients to be markedly changed after treatment, and again this varied according to different syndromes. The "other phobias" still retain a high improvement rate at the end of treatment but not at follow-up. Writer's cramp cases and obsessive rituals show a very poor response to behaviour therapy. Only one of those with writer's cramp was rated " much improved," another five being merely slightly improved.

Behaviour therapy is not a particularly brief treatment. Agoraphobias received most treatment, with a mean of 56 sessions over six months, while patients with "other phobias," who did best, received a mean of 27 sessions over four months.

Possible reasons for the poor result with writer's cramp were examined. All patients co-operated, some returning for a very large number of sessions without evidence of improvement. Many of our patients showed some other evidence of neurotic disturbance. Some improved during the sessions, and learning curves could be constructed to show their progress, but this did not extend outside the treatment sessions.

Evidence for fresh symptoms was sought in all cases. A few patients developed new symptoms during the period of followup, but these occurred as often in controls as in patients receiving behaviour therapy; therefore they are not a special hazard of behaviour therapy.

\section{General Discussion}

Only our overall improvement rate of $61 \%$ can be compared with the results of Wolpe $(1958,1964)$ and Lazarus (1963), as it is not clear how their patients with particular syndromes (rather than symptoms) fared. Our overall rate is similar to Lazarus's $61.9 \%$. When Wolpe's results are corrected for the number who dropped out (and who were not counted in the figure of $90 \%$ ), he obtained a $75 \%$ improvement rate in those starting treatment. This is still greater than our overall figure but only slightly more than the improvement rate obtained when our patients with obsessional rituals and writer's cramp are excluded $(70 \%)$. There were few of these patients in Wolpe's series.

Wolpe (1964) criticized Cooper's investigation on the grounds that the therapists were unskilled. Marks and Gelder (1965) analysed results according to type of therapist and found that those patients treated by therapists with extensive knowledge of learning theory (lecturers and senior lecturers in a university department of clinical psychology) did no better than those treated by others (student psychologists and psychiatric registrars). We consider that the relevant skills are derived 
more from clinical experience in treating neurotic patients than from detailed knowledge of learning principles.

Retreatment in two agoraphobics did not change their outcome, but was not given to patients with " other phobias." Improvement of the latter may conceivably have persisted longer with boosters after discharge.

\section{Results Considered by Diagnostic Groups}

\section{Phobic States (41 Patients)}

Results with agoraphobia at first appear encouraging but are not significantly different from those of a matched control group of patients treated by various forms of brief in-patient support and milieu therapy (see Table). Moreover, results with agoraphobia are less satisfactory than simple improvement figures suggest, since improvement was often of limited extent, and largely left patients with their original social handicaps.

In the " other phobias" group better immediate results were obtained: all improved during treatment, although some relapsed during follow-up, so that the final improvement rate was $67 \%$. Our controls were well matched for age and symptom duration. The immediate improvement rate is striking and significantly different from that of the controls $(\mathbf{P}<0.01)$; at the end of a year this is no longer so. It is noteworthy that mean symptom duration was 19 years in this group, who did well. Within the agoraphobias, symptom duration did not correlate with outcome. Symptom-duration does not therefore appear to be a crucial variable affecting response to treatment. Symptom type is far more important. It is clear that current techniques of behaviour therapy produced best results in those phobic patients in whom anxiety develops in relatively clear-cut circumstances and other neurotic symptoms are not widespread. Even so, treatment was lengthy.

Patients with agoraphobia are more common than patients with the "other phobias" and present a particularly difficult treatment problem. Roberts (1964) has shown that their prognosis is poor, and that the reported improvement rates of $60-80 \%$ hide much residual social disability. Behaviour therapy by " retraining" does not appear to alter the prognosis significantly compared with a matched control group which received much less treatment. This is not to say that agoraphobics should no longer be sent out for walks as part of their treatment-indeed, it is widely recognized that this has a part to play-but rather that to make this the focal point of treatment does not improve the results. Again, only a few of these patients had desensitization in imagination, which Wolpe (1958) claims is a more efficient method of treatment. A prospective investigation of patients with severe agoraphobia treated in this way in hospital did not confirm this (Gelder and Marks, 1965), but when less severe agoraphobics were treated as out-patients by desensitization in imagination, results were superior to those in out-patient controls, and to those in in-patients (Gelder et al., 1964). Wolpe (1964) also points out that there are often complicated social aspects to these cases which must be treated. We agree with this, but consider that once these are dealt with by traditional methods of social work, interviewing relatives, and discussing emotional problems, the behaviour therapy cannot be singled out as solely responsible for any improvement that occurs.

\section{Obsessional Patients (10 patients)}

The failure of 7 out of 10 obsessional patients to improve shows the limitations of behaviour therapy in its application to this type of symptom.

Wolpe $(1958,1964)$ gives a few examples of the successful treatment of obsessional patients, but it is not clear if there were others of this type who did not respond. He reports (Wolpe, 1964) the successful desensitization to urine of an obsessional boy in two stages, the first stage consisting of " about five months of sessions taking place about five times a week" (presumably about 100 sessions), followed by an unstated number of sessions in the second stage. This case report gives an indication of the time, patience, and ingenuity that behaviour therapy can demand.

\section{Writer's Cramp (13 patients)}

Behaviour therapy produced improvement in only $6(46 \%)$ out of 13 cases of writer's cramp in this series, and this improvement was very limited. This is in contrast to the results of Liversedge and Sylvester (1960), who treated 39 out of 56 patients referred to them for writer's cramp; $24(62 \%)$ of these were stated to have improved greatly. Thus their figures can be regarded either as a success rate of $62 \%$ of those treated or $47 \%$ of those referred for treatment. Only 10 of their patients showed some other evidence of neurotic disturbance, whereas many of ours showed this.

Writer's cramp has been treated before by various combinations of retraining, relaxation, and graded writing practice (Kihn, 1937 ; Ajuriaguerra et al., 1956). These treatments clearly have features commonly found in behaviour therapy programmes, and, although the latter are more systematically constructed and arise from a more elaborate theory, it is not certain that they produce superior results.

\section{Difference in Response Rates}

The necessity of reporting results by clinical groupings is illustrated by the very different response rates in our groups. The common report of $70 \%$ improvement in mixed groups of neurotic patients could have appeared to be substantiated by our $61 \%$ for all behaviour-therapy patients mixed together. This figure is misleading when it is seen that it is derived from disparate conditions the improvement rates of which vary from 0 to $100 \%$, depending on the syndrome, timing, and degree of improvement under consideration. The statement of Giel et al. (1964) that "any new treatment for the neuroses must show better than $70 \%$ improvement before it can claim to represent a significant therapeutic advance" is similarly misleading. Their figures could be reported as $86 \%$ improved (rather than their $71 \%$ ) if one included all their improvement categories together. In addition, their figures are five-year follow-up rates and may completely miss treatment effects which shortened suffering of self-limiting type, as these would no longer be detectable so long afterwards. We believe that results in the "other phobias" constitute a worth-while therapeutic advance even if one regards their rate of improvement as only $58 \%$ after treatment, diminishing with time, as this was the highest rate of any of our groups, and much higher than in the corresponding controls.

\section{The Patient-Therapist Relationship}

Intense feelings towards therapists developed in seven of our patients but this did not usually hinder therapy. Most patients were co-operative and had confidence in their therapists. This is a natural asset in any form of medical treatment, and it was not necessary to analyse such feelings to effect improvement. The few complications that did occur-usually intense attachment and dependency of the patient-indicate that it is necessary for behaviour therapists to be aware of their own responses during treatment. Only four patients were uncooperative to the extent of hindering behaviour therapy. It is an acceptable form of treatment for most, though a minority expressed a preference for a more psychodynamic approach. 


\section{Conclusions}

This critical evaluation of the available results of behaviour therapy must not be taken to imply that this method is of no value. In none of the groups considered was it less effective than other methods of treatment, and in the phobias it was more effective. The development of fresh symptoms was not a special hazard of behaviour therapy. It can be effective in severe chronic cases where other methods have been tried and have failed; and in some conditions-for example, rare monosymptomatic phobias-it may even be the first consideration for treatment. When individual patients are considered, behaviour therapy, like any other form of treatment, can occasionally produce startling and rapid improvements, but whether these result from enthusiasm, behaviour therapy, or other factors remains unknown.

Behaviour therapy techniques need not be seen as rivalling other therapies. Indeed, it is likely that their ultimate place will be alongside existing treatments with drugs and psychotherapy, in a particular group of neurotic disorders. At present the group which benefits most appears to consist of simple phobias (and possibly other conditions) where anxiety develops in relatively specific situations-in patients without widespread neurotic disturbance. It is suggested that the techniques should also be tried in other groups who share these characteristicspossibly in patients with social anxieties and some cases of asthma where attacks are related to specific situations. Meanwhile the experimental use of behaviour therapy should be continued, with the aim of developing new methods that will widen its range of usefulness, as, for example, the production of aversion by electric shock in transvestism and other sexual disorders. It would also be well worth while investigating its application to children's fears, such as school phobia.

\section{Summary}

Studies were made of 77 patients who received behaviour therapy in the Bethlem Royal and Maudsley Hospitals between 1956 and 1963. They were assessed and followed up for one year after treatment, together with matched control groups ( 55 patients). Assessment of symptoms was made blindly by two independent judges.

Twenty-nine severe agoraphobics did slightly but not significantly better than their 29 controls. Twelve "other phobics" -for example, animals, insects, thunder-showed far more improvement than 11 controls, this difference being significant at the end of treatment, but diminished and was no longer so after one year's follow-up. Differential response to treatment paralleled different clinical features of severe agoraphobia compared with other phobias. The latter were more continuous, much more circumscribed, with fewer other disturbances.

Results were poor in 13 patients with writer's cramp and 10 with obsessive rituals. Their corresponding controls also did poorly. Results were also poor in 13 patients with miscellaneous conditions.

It is concluded that behaviour therapy was useful in patients with circumscribed phobias, and is worth further application in other conditions in which anxiety is manifest in relatively specific situations.

The commonly reported figure of two-thirds improvement in mixed groups of neurotic patients is misleading in that it conceals marked differences in improvement rates from 0 to $100 \%$ in the course of different clinical syndromes, depending upon the timing and degree of improvement under consideration.

This work was made possible through the encouragement of Professor Sir Aubrey Lewis and a grant from the Medical Research Council. Thanks are due to Drs. H. Gwynne Jones, M. Rutter, and S. Rachman for helpful comments on the manuscript. Finally we wish to thank the psychiatrists who allowed us to follow up patients under their care, and those many general practitioners and psychologists who generously supplied us with essential information.

\section{REFERENCES}

Ajuriaguerra, J. de, Trillat, E., and Soutiran, G. (1956). Encéphale, 2,

Cooper, J. E. (1963). Lancet, 1, 411.

Eysenck, H. J. (editor) (1960). Behaviour Therapy and the Neuroses. Pergamon Press, Oxford.

Gelder, M. G., and Marks, I. M. (1965). In preparation.

Sakinofsky, I., and Wolff, H. H. (1964). Paper read to the Sixth International Congress of Psychotherapy, London. To be published.

Giel, R., Knox, R. S., and Carstairs, G. M. (1964). Brit. med. F., 2, 160.

Kihn, B. (1937). Nervenarzt, 10, 69.

Lazarus, A. A. (1963). Behav. Res. Ther., 1, 66.

Liversedge, L. A., and Sylvester, J. D. (1960). In Behaviour Therapy and the Neuroses, edited by H. J. Eysenck. Pergamon Press, Oxford.

Marks, I. M., and Gelder, M. G. (1965). Brit. F. Psychiat. In press.

Meyer, V., and Gelder, M. G. (1963). Ibid., 109, 19.

Roberts, A. H. (1964). Ibid., 110, 191.

Wolpe, J. (1958). Psychotherapy by Reciprocal Inhibition. Stanford Univ. Press, Stanford, California. (1964). Brit. f. Psychiat., 110, 28.

\title{
Effect of Prolonged Carbohydrate Restriction on Serum-insulin Levels in Mild Diabetes
}

\author{
P. A. RUDNICK, $* \dagger$ M.D. ; K. W. TAYLOR,* M.A., PH.D., M.B., B.CHIR.
}

Brit. med. Э., 1965, 1, 1225-1228

The beneficial effects of carbohydrate restriction in mild diabetes have now been documented for over a century (see Bouchardat, 1875 ; Naunyn, 1906). Much more recently the glucosetolerance curve has been shown to return virtually to normal in some obese diabetics after a period of carbohydrate restriction (Newburgh and Conn, 1939; Himsworth, 1949). There are

\footnotetext{
* Department of Medicine and Diabetic Department, King's College Hospital, London.

† United States Public Health Service Research Fellow. Present address, University of California, L.A. Medical School, Los Angeles.
}

two possible mechanisms for a change of this kind. Thus tolerance might be improved because of an increased effectiveness of circulating insulin. This could be due, for example, to a lessening of insulin antagonism. Alternatively, there might be an improvement in the ability of the pancreas to secrete insulin so that more insulin was available following the stimulus due to oral glucose. This last possibility has been investigated.

Below are reported in detail the changes in the serum-insulin response to glucose during a period of carbohydrate restriction in a group of mild diabetics. The results in this group are 